\title{
Lymphocytic infiltration and survival in rectal cancer
}

\author{
JR JASS \\ From the Imperial Cancer Research Fund Colorectal Cancer Unit, St Mark's Hospital, and the Department of \\ Histopathology, Medical College of St Bartholomew's Hospital, London
}

SUMMARY Lymphocytic infiltration was assessed semiquantitatively in 447 specimens of rectal cancer. Corrected five year survivals for pronounced, moderate, and little lymphocytic infiltration were $92 \%, 65 \%$ and $36 \%$, respectively. Grading was shown to be reproducible in an intraobserver study (observed agreement $81 \%$, expected agreement $34 \%$, kappa coefficient 0.72 ). In the multivariate survival analysis of grade and stage related variables lymphocytic infiltration was the only grade related variable to be accepted within the prognostic model. This model also included the number of lymph node metastases and the extent of tumour spread.

It is suggested that the conservation of the normal interactive traffic between epithelium and mucosa associated lymphoid tissue (MALT) signals a low grade growth.This is supported by the association between lymphocytic infiltration and the expression of secretory component by malignant epithelium.

The survival advantage of a pronounced lymphocytic infiltration in specimens of large bowel cancer has been known for many years. MacCarty ${ }^{1}$ commented on the benefit of lymphocytic infiltration in 1931, and his observations have been endorsed and amplified in subsequent communications. ${ }^{2-9}$ None of these studies has allowed the grade of lymphocytic infiltration to compete with more traditional variables by the method of multivariate survival analysis, using the proportional hazards regression model. ${ }^{1011}$ Such a statistical manoeuvre would allow the independent effect of lymphocytic infiltration on survival to be separated from other prognostic variables.

\section{Material and methods}

Sections from 447 unselected specimens of rectal cancer, which had been removed by radical surgery between 1960 and 1965, were examined. Cancers complicating chronic inflammatory bowel disease and familial polyposis coli were excluded, as were specimens removed from patients who had died within 28 days of surgery. Patients were followed up. for at least 15 years, or until death. Details of follow up procedures and documentation have been published previously. ${ }^{12}$

Lymphocytic infiltration was graded as being pronounced, moderate, and little or none, and this assessment was made at the advancing front of the tumour. The lymphocytic infiltrate was usually distributed

Accepted for publication 30 January 1986 within a delicate connective tissue lamina at the growing tumour margin (Fig. 1). Other inflammatory cells were also represented. The lamina closely resembled normal lamina propria and followed the advancing edge of the tumour in a sleeve like manner. When the tumour invaded in a more nodular fashion the lymphocytic infiltrate was arranged in a cap. Little or no lymphocytic infiltration is self explanatory, and moderate infiltration implied a broken or imperfectly formed lamina with relatively few lymphocytes. Assessment was based on the worst area. Details of other discrete grade related variables (Table 1) have been published separately. ${ }^{13}$ Three months after the completion of the study 50 consecutive cases were regraded and intraobserver agreement was measured by the kappa coefficient. ${ }^{14}$

Stage related data were obtained from the records of St Mark's Hospital (Table 1).

Variables were analysed by standard survival methods and by multivariate analysis using the proportional hazards regression model. ${ }^{1011}$ Deaths from causes other than rectal cancer were treated as censored observations at the time of death. In this way lymphocytic infiltration was directly linked with tumour behaviour. Variables were chosen by the forward stepwise regression model using the BMDP2L program. Using this method, the independent effect of lymphocytic infiltration on survival was separated from the other prognostic variables.

Twenty two tumours with pronounced lymphocytic infiltration and 23 with little or no lymphocytic infiltration were stained by secretory component (Da- 


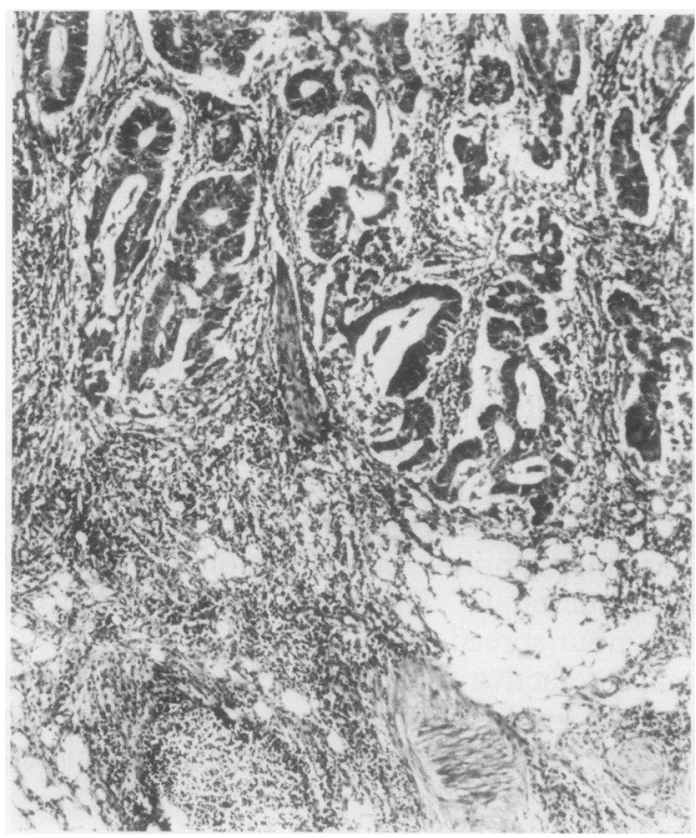

Fig. 1 This section shows pronounced lymphocytic infiltrate that is not limited to advancing edge of tumour, but extends into stroma surrounding malignant epithelium (Haematoxylin and eosin) $\times 30$.

Table 1 Pathological variables to compete with lymphocytic infiltration in proportional hazards regression model

Grade related

Type: papillary, tubular, mucinous, signet ring

Tubule configuration: regular, irregular, none

Nuclear polarity: easily discerned, just discerned, lost

Pattern of growth: expanding, infiltrating

Fibrosis: little, average, pronounced

Stage related

No of affected nodes: $0,1-4, \geqslant 5$

Spread beyond wall: none, slight, extensive

Extramural venous invasion: no, yes

kopatts), using an indirect immunoperoxidase technique. Details of methodology and controls have been published previously. ${ }^{15}$ Staining was graded positive or negative.

\section{Results}

The influence of lymphocytic infiltration on survival is shown by Kaplan-Meier survival curves (Fig. 2), and Table 2 shows the corresponding data. Lymphocytic infiltration was influenced by Dukes' stage, with $53 \%, 28 \%$, and $13 \%$ of Dukes' $A, B$, and $C$ cases (respectively), showing pronounced lymphocytic infiltration. An important independent effect of lym-

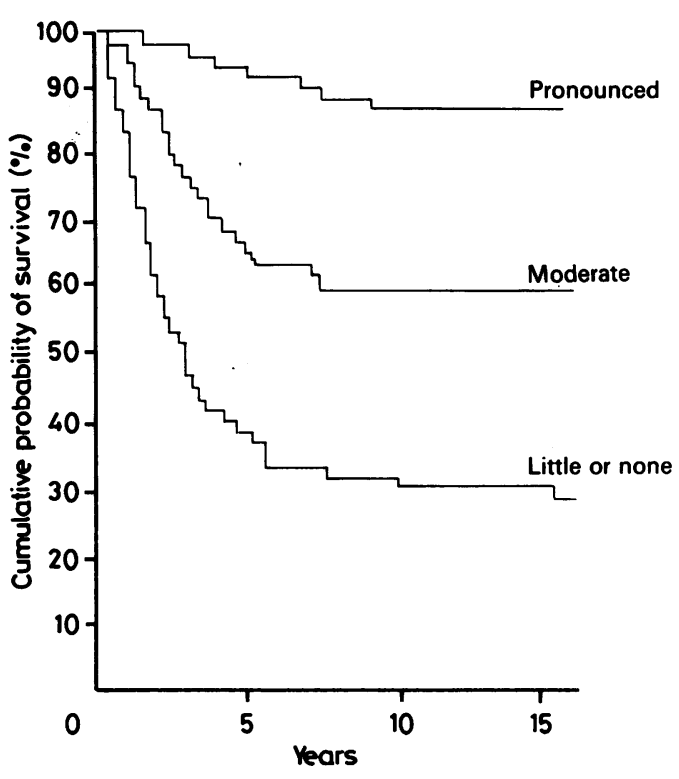

Fig. 2 Kaplan-Meier survival curves for lymphocytic infiltration.

No of lymph

nodes affected

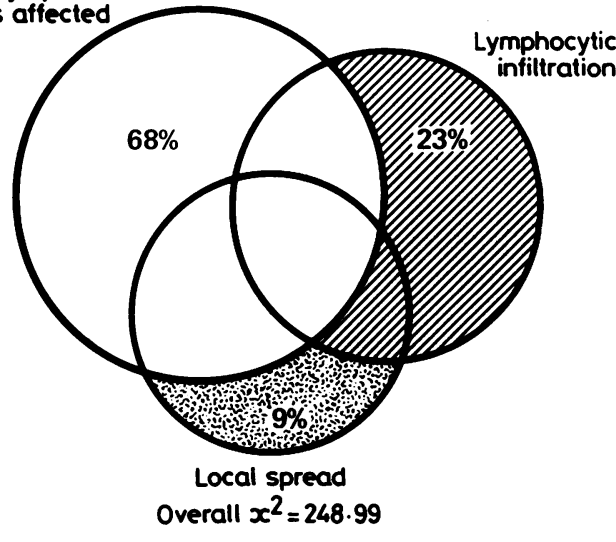

Fig. 3 Venn diagram depicting stepwise addition of variables and their independent contribution to overall likelihood ratio $\chi^{2}$. Best fitting model was constructed by selecting variable with highest likelihood ratio $\chi^{2}$ at step 0 (Table 3). On entering node status, $\chi^{2}$ is recomputed to show only independent contribution of remaining variables. Highest $\chi^{2}$ is again entered and process continues until no significant improvement in $\chi^{2}$ occurs. Size of circles is proportional to individual $\chi^{2}$ at step 0 of Table 3 (univariated analysis). Percentages refer to size of independent contribution within overall $\chi^{2}$, as determined by multivariate $\mathbb{D}$ analysis. 
Table 2 Lymphocytic infiltration and survival rates in rectal cancer (figures in parentheses are numbers \%)

\begin{tabular}{llclcc}
\hline Lymphocytic infiltration & No of patients & $\begin{array}{l}\text { Observed No of } \\
\text { deaths }\end{array}$ & $\begin{array}{l}\text { Deaths } \\
(\text { O/E) }\end{array}$ & \begin{tabular}{l} 
Corrected five year $\begin{array}{l}\text { Corrected 10 year } \\
\text { survival (\%) }\end{array}$ \\
\hline survival (\%)
\end{tabular} \\
\hline Pronounced & $110(25)$ & 13 & $0 \cdot 21$ & 92 & 87 \\
Moderate & $152(34)$ & 55 & 0.80 & 65 & 61 \\
Little or none & $185(41)$ & 123 & $2 \cdot 00$ & 36 & 30 \\
\hline
\end{tabular}

$\chi^{2}$ trend $=99 \cdot 6 ; \mathrm{p}<0.0001$ (based on logrank analysis of entire survival curve); $\mathrm{O}=$ observed; $\mathrm{E}=$ expected.

Table 3 Selection of regression model for grade and stage related variables

\begin{tabular}{|c|c|c|c|c|}
\hline \multirow[t]{2}{*}{ Variables } & \multicolumn{4}{|c|}{ Likelihood of ratio $\chi^{2}$ to enter into model } \\
\hline & Step 0 & Step I & Step 2 & Step 3 \\
\hline $\begin{array}{l}\text { Adenocarcinoma type } \\
\text { Tubule configuration } \\
\text { Pattern of growth } \\
\text { Nuclear polarity } \\
\text { Fibrosis } \\
\text { Lymphocytic infiltration } \\
\text { No of affected nodes } \\
\text { Spread through bowel wall } \\
\text { Vein invasion } \\
\text { Overall likelihood ratio } \chi^{2}\end{array}$ & $\begin{array}{r}17.73 \\
80.15 \\
89.54 \\
38.38 \\
19 \cdot 20 \\
106.84 \\
168.43 \\
112.14 \\
29.93\end{array}$ & $\begin{array}{c}6 \cdot 54 \\
30 \cdot 05 \\
44 \cdot 23 \\
15 \cdot 38 \\
3.61 \\
57 \cdot 74 \\
168 \cdot 43^{*} \\
47 \cdot 87 \\
10.84 \\
p<0.0001 \\
168 \cdot 43(\mathrm{df})\end{array}$ & $\begin{array}{c}2 \cdot 60 \\
6 \cdot 26 \\
9 \cdot 91 \\
2 \cdot 13 \\
0 \cdot 71 \\
57 \cdot 74^{*} \\
119 \cdot 33^{*} \\
22 \cdot 82 \\
2 \cdot 27 \\
p<0.0001 \\
226 \cdot 17(2 \mathrm{df})\end{array}$ & $\begin{array}{c}1 \cdot 84 \\
3 \cdot 83 \\
5 \cdot 40 \\
1 \cdot 13 \\
0 \cdot 89 \\
32 \cdot 70^{*} \\
77 \cdot 78^{*} \\
22 \cdot 82^{*} \\
0.76 \\
\text { p }<0.0001 \\
248.99(3 \mathrm{df})\end{array}$ \\
\hline
\end{tabular}

RMDP2L program calculates likelihood ratio $\chi^{2}$ from survival analysis. Step 0 shows univariate analysis and forward stepwise entry follows in steps 1,2 , and 3 to achieve multivariate analysis.

*denotes that variable has been entered into model.

phocytic infiltration on survival was shown, however, by multivariate analysis (Table 3 ). The prognostic model is most easily appreciated by a Venn diagram (Fig. 3). This shows the magnitude of the contribution made by variables as they were chosen in steps, until no further clinical benefit was derived. Grading of lymphocytic infiltration was reproducible with an observed agreement of $81 \%$, expected agreement of $34 \%$, and kappa coefficient of 0.72 . No pronounced case was regraded little or none (or vice versa).

Nineteen of the 22 cases with severe lymphocytic infiltration showed positive secretory component staining by malignant epithelium, whereas only six of the 23 cases with few or no lymphocytes gave a positive result $\left(\chi^{2}=16.55 ; \mathrm{p}<0.01\right)$.

\section{Discussion}

This study confirms the survival advantage of a pronounced lymphocytic infiltrate in specimens of rectal adenocarcinoma. ${ }^{1-9}$ It is the first study, however, to show that the effect is partly independent from other pathological variables. Practical applications of this observation have been presented in detail elsewhere. ${ }^{13}$

The role of immune mechanisms in the pathogenesis and spread of cancer has been debated for many years. There are two explanations for the results of this study that are not necessarily mutually exclusive. Firstly, the lymphocytic infiltrate could represent a specific response by the host against the tu- mour. Secondly, the inflammatory lamina at the advancing front of the tumour may be closely related to the normal lamina propria in terms of its structure and function. The persistence of the normal channels of communication between epithelium and mucosa associated lymphoid tissue (MALT) might signal a high level of functional differentiation.

The proportions of lymphocyte subsets are changed in the malignant stroma of colorectal cancers compared with those of normal lamina propria, with an increased cytotoxic-suppressor:helper $T$ cell ratio. ${ }^{1617}$ Reduced numbers of IgA secreting plasma cells have been observed, whereas IgG secreting plasma cells may be more numerous. ${ }^{18}$ Macrophages have been detected in greatly increased numbers. ${ }^{18}$ These modulations indicate that immune mechanisms were operating within the stroma surrounding neoplastic epithelium. No correlations, however, between lymphocyte subset numbers and stage of disease have been described. ${ }^{1819}$ Increased numbers of macrophages ${ }^{18}$ and extensive fibrosis ${ }^{13}$ have been found in advanced cases of rectal cancer. It is important to appreciate that most of these studies have relied on small samples of frozen tissue, which may not have been sufficiently representative.

Some in vitro studies support the existence of specific antitumour immunity. A leucocyte inhibition assay was positive in $41 \%$ of patients with colorectal cancer but only $6 \%$ of treated patients with no clinical evidence of residual disease. The incidence of positive results was highest in early cancers and lowest when 
tumours were widely disseminated. ${ }^{20}$ Specific cellular immunity has also been shown by a cell migration inhibition test. This was positive in $89 \%$ of patients with colorectal cancer, $63 \%$ of patients with adenomas, but only $10 \%$ of healthy control subjects. ${ }^{21} \mathrm{~A}$ cytotoxic assay using tumour infiltrating lymphocytes showed that increased cytotoxicity was associated with longer survival. ${ }^{22}$ Cytotoxic-suppressor $\mathrm{T}$ cells might destroy tumour cells that simultaneously express major histocompatibility (HLA) class I antigens and tumour associated neoantigens. The neoexpression of class II determinants (HLA-DR) might further increase or restrict the $T$ lymphocyte response. ${ }^{1617}$ It has been found, however, that class I positive tumours are not associated with increased lymphocytic infiltration, ${ }^{16}$ nor is $\mathrm{T}$ cell infiltration accompanied by overt evidence of cytodestruction. ${ }^{16}$ Natural killer cells are conspicuous by their absence from colorectal cancer infiltrates. ${ }^{1619}$ Other mechanisms could be relevant including the production of lymphokines. $\gamma$ Interferon slows tumour growth in vitro $^{23}$ and $\alpha$ and $\beta$ interferon are known to influence the differentiation of cultured colorectal cancer cells. ${ }^{24}$ This in turn could modulate tumour behaviour. On the other hand, $\alpha$ interferon stimulates tumour growth in human colorectal cancer transplanted into nude mice. ${ }^{25}$

Several studies have shown a correlation between reactive lymph node changes and survival in large bowel cancer. Hyperplasia of the paracortical zone, ${ }^{26-28}$ hyperplasia of germinal centres, ${ }^{27-30}$ and sinus histiocytosis ${ }^{26}$ confer a survival advantage. Reactive hyperplasia in lymph nodes containing metastases identifies Dukes' C cases with a good prognosis. ${ }^{30}$

In this study the peritumoral lymphocytic infiltrate was often arranged within a delicate stromal lamina that followed the contour of the advancing front of the tumour. There was a distinct resemblance to the normal lamina propria. It is possible, therefore, that the observation of a pronounced lymphocytic infiltrate simply reflects the persistence of normal epithelial-stromal interaction. The ratios of lymphocyte subsets may be changed, and lymphocyte numbers may possibly be increased through the neoexpression of major histocompatibility complex class II antigens ${ }^{31}$ and tumour associated antigens. Such modulations could, however, be epiphenomena with the survival advantage being due to the underlying preservation of epithelial-stromal communications. This would in turn signal a high level of functional differentiation and hence a low grade growth. One effector arm of the normal epithelialstromal interactive unit is the cellular translocation of IgA (linked to secretory component). The loss of epithelial staining for secretory component accompanies loss of differentiation. ${ }^{32} 33$ This observation provides indirect support for the second hypothesis. The asso-음 ciation between lymphocytic infiltration and expression of secretory component by malignanto epithelium, as shown by this study, adds further indi-O rect support to the hypothesis. It is possible that the in vitro studies described above identified an epiphe- $\frac{\bar{\omega}}{\bar{T}}$ nomenon that could not arise without the persistence $\stackrel{\mathbb{\Phi}}{\Phi}$ of epithelial-stromal interactions at the tumour inter-o face. The same argument might apply to the lymph $\stackrel{0}{\circ}$ node changes.

The conclusion of this paper is that the presence of $\vec{\omega}$ a peritumoral lymphocytic infiltrate is an importanto independent prognostic marker, second only to the number of lymph node metastases. This finding, how- $\dot{\omega}$ ever, is unlikely to indicate the successful limitation of growth by a specific immune response and probablyer represents the persistence of epithelial-stromal inter-or actions, or both, that become secondarily modifiedo and increased through the anomalous presentation of tumour associated and major histocompatibility com- $-\frac{C}{\subseteq}$ plex class II antigens.

I thank WS Atkin and J Cuzick for their statisticalo support, $\mathbf{K}$ Miller and J England for technical help; and Jill Grimsey for typing the manuscript.

\section{References}

${ }^{1}$ MacCarty WG. Principles of prognosis in cancer. JAMA 1931;96:30-3

${ }^{2}$ Murray D, Hren A, Dutton J, Hampson LG. Prognosis in colon3 cancer. A pathologic assessment. Arch Surg 1975;110:908-13. ᄀ

${ }^{3}$ Zamcheck N, Doos WG, Prudente R, Lurie BB, Gottlieb LS. Prog nostic factors in colon carcinoma. Correlation of serum carcino- embryonic antigen level and tumor histopathology. Hum Pathot] 1975;6:31-45.

${ }^{4}$ Watt AG, House AK. Colonic carcinoma. A quantitative assessment of lymphocyte infiltration at the periphery of colonic tumors related to prognosis. Cancer 1978;41:279-82.

${ }^{5}$ Thynne GS, Weiland LH, Moertel CG, Silvers A. Correlation of histopathologic characteristics of primary tumor and uninvolved regional nodes in Dukes' $\mathrm{C}$ colonic carcinoma with prog-글 nosis. Mayo Clin Proc 1980;55:243-5.

${ }^{6}$ de Mascarel A, Coindre JM, de Mascarel I, Trojani M, Maree D, Hoerni B. The prognostic significance of specific histologic features of carcinoma of the colon and rectum. Surg Gynecol Obstet 1981;153:511-4.

${ }^{7}$ Zhou X-G, Yu BM, Shen Y-X. Surgical treatment and late results in 1226 cases of colorectal cancer. Dis Colon Rectum N 1983;26:250-6.

${ }^{8}$ Carlon CA, Fabris G, Arslan-Pagnini C, Pluchinotta AM, Chinelli< K, Carniato S. Prognostic correlations of operable carcinoma of the rectum. Dis Colon Rectum 1984;28:47-50.

${ }^{9}$ Svennevig JL, Lunde OC, Holter J, Bjorgsvik D. Lymphoides infiltration and prognosis in colorectal carcinoma. $\mathrm{Br} \mathrm{J}$ Cancer 1984;49:375-7.

${ }^{10}$ Cox DR. Regression models and life tables (with discussion). Jour $\frac{\vec{D}}{(\Phi)}$ nal of the Royal Statistical Society B 1972;34:187-200.

11 Freedman LS, Macaskill P, Smith AN. Multivariate analysis of prognostic factors for operable cancer. Lancet 1984;ii:733-6.

12 Talbot IC, Ritchie S, Leighton M, et al. Invasion of veins by car 
cinoma of rectum: methods of detection, histological features and significance. Histopathology 1981;5:141-63.

13 Jass JR, Atkin WS, Cuzick J, et al. The grading of rectal cancer. Historical perspectives and a multivariate analysis of 447 cases. Histopathology (in press).

${ }^{14}$ Landis JR, Koch GG. The measurement of observer agreement for categorical data. Biometrics 1977;33:159-74.

15 Jass JR, Faludy J. Immunohistochemical demonstration of IgA and secretory component in relation to epithelial cell differentiation in normal colorectal mucosa and metaplastic polyp: a semiquantitative study. Histochem $J$ 1985;17:373-80.

${ }^{16}$ Csiba A, Whitwell HL, Moore M. Distribution of histocompatibility and leucocyte differentiation antigens in normal human colon and in benign and malignant colonic neoplasms. Br J Cancer 1984;50:699-709.

${ }^{17}$ Umpleby HC, Heinemann D, Symes MO, Williamson RCN. Expression of histocompatibility antigens and characterisation of mononuclear cell infiltrates in normal and neoplastic colorectal tissues of humans. $J N C I$ 1985;74:1161-8.

${ }^{18}$ Allen C, Hogg N. Monocytes and other infiltrating cells in human colorectal tumors identified by monoclonal antibodies. Immunology 1985;55:289-99.

${ }^{19}$ Koch B, Griedl J, Hermanek P, Kalden JR. The analysis of mononuclear cell infiltrations in colorectal adenocarcinoma. $J$ Cancer Res Clin Oncol 1985;109:142-51.

${ }^{20}$ Fink A, Shani A, Weisman Z, et al. Leukocyte adherence inhibition (LAI) for detecting specific tumor immunity in colorectal cancer. Immunol Lett 1985;9:143-7.

${ }^{21}$ Muhrer KH, Padberg W. Detection of colorectal cancer and precancerous lesions by means of anti-tumor immunity. Clin Cancer Res 1984;3:367-75.

${ }^{22}$ Hutchinson GH, Umpleby HC, Ranson DL, Symes MO, Williamson RCN. Prognostic value of in-vitro tests of lymphocyte reactivity in colorectal carcinoma. Journal of Experimental and Clinical Cancer Research 1983;2:161-6.

${ }^{23}$ Schwartz R, Momburg F, Moldenhauer G, Dorken B, Schirrmacher V. Induction of HLA class III antigen expression on human carcinoma cell lines by IFN-gamma. Int $J$ Cancer 1985;35:245-50.
${ }^{24}$ Chanh TC, Seh ML, Dookhan MJ, Lake P. Modulation by recombinant $\alpha$ and $\beta$ IFN of the expression of a human colon adenocarcinoma-associated antigen. Fed Proc 1985;44:791.

${ }^{25}$ Schmitz R, Gerdts-Mueller C, Seidler C, Mohr H, Izbicki JR. Human $\alpha$-interferon induced stimulation of tumor growth of human colorectal adenocarcinomas xenotransplanted onto nude mice. Journal of Experimental and Clinical Cancer Research 1984;3:463-73.

${ }^{26}$ Patt DJ, Brynes RK, Vardiman JW, et al. Mesocolic lymph node histology is an important prognostic indicator with patients with carcinoma of the sigmoid colon: an immunomorphologic study. Cancer 1975;35:1388-97.

${ }^{27}$ Pihl E, Nairn RC, Nind AP, et al. Correlation of regional lymph node in vitro antitumour immunoreactivity histology with colorectal carcinoma. Cancer Res 1976;36:3665-71.

${ }^{28}$ Pihl E, Malahy MA, Khankhanian $\mathrm{N}$, et al. Immunomorphological features of prognostic significance in Dukes' class B colorectal carcinomas. Cancer Res 1977;37:4145-9.

${ }^{29}$ Tsakraklides V, Wanebo HJ, Sternberg SS, et al. Prognostic evaluation of regional lymph node morphology in colorectal cancer. Am J Surg 1975;129:174-80.

${ }^{30}$ Pihl E, Nairn R, Milne BJ, et al. Lymphoid hyperplasia: a major prognostic feature in 519 cases of colorectal carcinoma. Am J Pathol 1980;100:469-80.

${ }^{31}$ Lampert IA, Kirkland S, Farrell S, Borysiewicz LK. HLA-DR expression in a human colon carcinoma cell line. J Pathol 1985;146:337-44.

${ }^{32}$ Isaacson P. Immunoperoxidase study of the secretory immunoglobulin system in colonic neoplasia. J Clin Pathol 1982;34:13-25.

${ }^{33}$ Arends JW, Wiggers T, Thijs CT, Verstijnen C, Swaen GJV, Bosman FT. The value of secretory component (SC) immunoreactivity in diagnosis and prognosis of colorectal cancers. Am J Clin Pathol 1984;82:267-74.

Requests for reprints to: Dr JR Jass, St Mark's Hospital, City Road, London EC1V 2PS, England. 